\title{
Epigallocatechin-3-gallate induces the apoptosis of hepatocellular carcinoma LM6 cells but not non-cancerous liver cells
}

\author{
YUNJUAN ZHANG $^{1}$, WEI DUAN ${ }^{2}$, LAWRENCE OWUSU ${ }^{1}$, DACHANG WU $^{1}$ and YI XIN ${ }^{1}$ \\ ${ }^{1}$ Department of Biotechnology, Dalian Medical University, Dalian, Liaoning 116044, P.R. China; \\ ${ }^{2}$ School of Medicine, Deakin University, Victoria 3216, Australia
}

Received March 28, 2014; Accepted September 17, 2014

DOI: $10.3892 /$ ijmm.2014.1988

\begin{abstract}
Epigallocatechin-3-gallate (EGCG) is a constituent of green tea and has been associated with anticancer activity. In the present study, the inhibitory effect of EGCG on human hepatocellular cancer cells was examined by cell viability assay, in vitro apoptosis assay and cell cycle analysis. In addition, gene expression was measured to elucidate the molecular mechanisms of action of EGCG by mitochondrial membrane potential (MMP) determination and western blot analysis. We demonstrated that EGCG induced apoptosis, decreased mitochondrial membrane potential and promoted $\mathrm{G}_{0} / \mathrm{G}_{1}$ phase cell cycle arrest of HCCLM6 cells but not that of non-cancerous liver cells (HL-7702). The EGCG-induced apoptosis of HCCLM6 cells was associated with a significant decrease in Bcl-2 and NF- $\mathrm{B}$ expression. In addition, the expression of Bax, p53, caspase-9 and caspase- 3 increased, and cytochrome $c$ was released. These results suggest that EGCG inhibits the progression of cancer through cytocidal activity and that it is a potential therapeutic compound for hepatocellular carcinoma (HCC).
\end{abstract}

\section{Introduction}

Hepatocellular carcinoma (HCC) is a malignant tumor with a high prevalence in Asia and Africa (1). HCC is the third most common cause of cancer-related mortalities $(500,000$ mortalities per year) and the fifth most common cancer worldwide (2). Treatments for HCC include percutaneous ethanol injection therapy, transcatheter arterial chemoembolization, liver transplantation and surgical intervention. Of these treatments, surgical intervention is the most effective for improving the 5-year survival rate of patients (3). One major obstacle for the optimum treatment of HCC is the high expression of anti-apoptotic genes, which contributes to an extremely poor

Correspondence to: Professor Yi Xin, Department of Biotechnology, Dalian Medical University, 9 Western Section of Lushun South Road, Dalian, Liaoning 116044, P.R. China

E-mail: jimxinzyj@sina.cn

Key words: epigallocatechin-3-gallate, hepatocellular carcinoma, apoptosis prognosis $(4,5)$. Therefore, novel or additional therapeutic strategies for HCC are required to circumvent this challenge.

Catechins constitute $\sim 40 \%$ of the dry weight of green tea, and epigallocatechin-3-gallate (EGCG) is the most common catechin (6-8). EGCG has great potential as an inexpensive, bioavailable chemotherapeutic agent for cancer prevention and complementary treatment (9). The anticancer role of EGCG has been studied epidemiologically in in vitro and in vivo systems, and in clinical trials (10-12). In vitro studies have demonstrated that EGCG inhibits cancer by inducing apoptosis (11-13). Several studies have also reported its role in cancer prevention via the induction of apoptosis, alteration of protein expression and inhibition of intracellular communication pathways (14-17). Apoptosis is driven by two major pathways: The cell death receptor-mediated extrinsic pathway and the mitochondria-mediated intrinsic pathway. However, the precise mechanism by which EGCG exerts its anticancer effects remains unknown.

There is a lack of studies describing the effect of EGCG on HCCs, compared to other cancers (18-20). To the best of our knowledge, no comparative studies of the effects of EGCG on HCCLM6 (a human HCC metastatic cell line) and HL-7702 (a non-cancerous, normal human liver cell line) cells have been reported. The present study investigated the potential effect of EGCG on these cell lines and the molecular mechanism of EGCG induced apoptosis of HCCLM6 cells.

\section{Materials and methods}

Antibodies and reagents. Dulbecco's modified Eagle's medium (DMEM) and fetal bovine serum (FBS) were purchased from Gibco (Grand Island, NY, USA). EGCG ( $\geq 98 \%$ purity), 3-(4,5-dimethylthiazol-2-yl)-2,5-diphenyltetrazolium bromide (MTT) and 4',6-diamidino-2-phenylindole (DAPI) were provided by Sigma (St. Louis, MO, USA). The fluorescein isothiocyanate (FITC)-conjugated anti-Annexin $\mathrm{V}$ and propidium iodide (PI) Dye Apoptosis Detection kit, the JC-1 Mitochondrial Membrane Potential Detection kit, the Cell Cycle Detection kit and the BCA Protein Assay kit were purchased from Nanjing KeyGen Biotech., Co., Ltd. (Nanjing, China). The SuperSignal ${ }^{\circledR}$ West Pico Trial kit was purchased from Thermo Scientific (Rockford, IL, USA). Mouse anti-human $\beta$-actin (sc-1496), mouse anti-human caspase-3 (sc-65497), mouse anti-human Bax (sc-7480), rabbit anti-human B-cell lymphoma 2 (Bcl-2) (sc-783) and horseradish peroxidase (HrP)-conjugated 
anti-rabbit or anti-mouse secondary antibodies were purchased from Santa Cruz Biotechnology, Inc. (Santa Cruz, CA, USA). Mouse anti-human p53 (AP062), rabbit anti-human nuclear factor- $\kappa \mathrm{B}(\mathrm{NF}-\kappa \mathrm{B})(\mathrm{AN} 365)$, mouse anti-human caspase-9 (AC062), mouse anti-human cytochrome $c$ (AC909), rabbit antihuman cyclooxygenase (COX) IV (AC610) were purchased from Beyotime Institute of Biotechnology (Beijing, China).

Cells and cell culture. HCCLM6 cells (ATCC, Rockefeller, MD, USA) and HL-7702 liver cells (Shenke Biological Technology, Co., Ltd., Shanghai, China) were grown in DMEM supplemented with $10 \%$ FBS, $0.1 \%$ benzyl penicillin and streptomycin. The cells were maintained at $37^{\circ} \mathrm{C}$ in a humidified incubator containing $5 \% \mathrm{CO}_{2}$. The cells were treated with varying concentrations of EGCG dissolved in serum-free medium.

Cell viability assay. HCCLM6 and HL-7702 cells $\left(6 \times 10^{3}\right.$ cells/well) were incubated in 96-well plates for $24 \mathrm{~h}$. This was followed by $24 \mathrm{~h}$ incubation of HCCLM6 cells with $0,5,10,20,30,40,60,80$, and $100 \mu \mathrm{g} / \mathrm{ml}$ EGCG and incubation of HL-7702 cells with $0,5,10,20,40,60,80,100,140$, 180,220 , and $260 \mu \mathrm{g} / \mathrm{ml}$ EGCG. At the end of the treatment, the culture supernatant was replaced with fresh complete medium containing $0.5 \mathrm{mg} / \mathrm{ml} \mathrm{MTT}$, and the cells were incubated at $37^{\circ} \mathrm{C}$ for $4 \mathrm{~h}$. The medium was discarded and replaced by dimethyl sulfoxide, and the cells were subjected to $10 \mathrm{~min}$ of gentle agitation. Absorbance was subsequently measured at $490 \mathrm{~nm}$. The assay was repeated three times. The growth inhibition rates of the cells were calculated according to the formula: Inhibition rate $(\%)=(1-$ mean absorbance of treated group/mean absorbance of untreated group) x $100 \%$.

Characterization of nuclear morphology. A nuclear DAPI dihydrochloride-staining assay was conducted to detect apoptosis. HCCLM6 and HL-7702 cells $\left(1 \times 10^{5}\right.$ cells/ml) were seeded onto $1-\mathrm{cm}$ plates and incubated at $37^{\circ} \mathrm{C}$ overnight. The cells were treated with 0,10 and $30 \mu \mathrm{g} / \mathrm{ml} \mathrm{EGCG} \mathrm{and}$ incubated for an additional $24 \mathrm{~h}$. The cells were washed once with phosphate-buffered saline (PBS), fixed with $4 \%$ paraformaldehyde for $15 \mathrm{~min}$, washed with PBS and air-dried. The cells were stained with DAPI at room temperature for $20 \mathrm{~min}$, washed with PBS and covered with Anti-Fade Fluoromount-G (Beyotime, Shanghai, China). Stained cells were observed and images captured at magnification, x400, with a fluorescent microscope (Leica, ELS, Wetzlar, Germany) equipped with a Nikon camera (Nikon, Tokyo, Japan).

In vitro apoptosis assay. HCCLM6 and HL-7702 cells ( $3 \times 10^{5}$ cells/well) were seeded into 6-well plates. At $80 \%$ confluency, the cells were treated with 0,10 , and $30 \mu \mathrm{g} / \mathrm{ml} \mathrm{EGCG}$ and incubated for $24 \mathrm{~h}$. The cells were harvested, washed with PBS and stained with the FITC-conjugated anti-Annexin V and PI Dye Apoptosis Detection kit according to the manufacturer's protocol. The apoptotic stage of the cells was analyzed using a flow cytometer (BD Biosciences, Franklin Lakes, NJ, USA).

Cell cycle analysis. HCCLM6 and HL-7702 cells were seeded into 6 -well plates $\left(6 \times 10^{5}\right.$ cells/well). At $80 \%$ confluency, the cells were treated with EGCG $(0,10$ and $30 \mu \mathrm{g} / \mathrm{ml})$ and incubated for $24 \mathrm{~h}$. The cells were harvested, washed with PBS and fixed in a $70 \%$ methanol solution at $4{ }^{\circ} \mathrm{C}$ for $24 \mathrm{~h}$. Following fixation, the cells were washed with PBS and stained using the Cell Cycle Detection kit according to the manufacturer's instructions. The cell cycle distribution was analyzed using a flow cytometer (BD Biosciences).

Mitochondrial membrane potential (MMP) determination. HCCLM6 and HL-7702 cells were seeded into 6-well plates $\left(6 \times 10^{5}\right.$ cells/well). At $80 \%$ confluency, the cells were treated with EGCG $(0,10$ and $30 \mu \mathrm{g} / \mathrm{ml})$ and incubated for 24 h. Cells were harvested, washed with PBS and stained with the JC-1 Mitochondrial Membrane Potential Detection kit according to the manufacturer's instructions. The MMP was analyzed using a flow cytometer (BD Biosciences).

Western blot analysis. HCCLM6 cells $\left(1 \times 10^{7}\right)$ were seeded into a T-25 culture flask and incubated until $80 \%$ confluency was achieved. The cells were treated with 0,10 and $30 \mu \mathrm{g} / \mathrm{ml}$ EGCG and incubated for $24 \mathrm{~h}$. Total cell protein was extracted from the treated cells and quantified with the BCA Protein Assay kit. Bovine serum albumin was used as the standard. Protein $(80 \mu \mathrm{g})$ was separated on a $12 \%$ SDS-PAGE gel and transferred to nitrocellulose membranes with a semi-dry transfer unit (Jim-X Biotechnology, Co., Ltd., Dalian, China). The membranes were treated with a 5\% skimmed dry milk-Tris-buffered saline with Tween 20 (TBST) solution at $37^{\circ} \mathrm{C}$ for $2 \mathrm{~h}$. Antibodies against p53, NF-кB, caspase-3, caspase-9, Bcl-2, Bax, cytochrome $c$, COX IV and $\beta$-actin in $5 \%$ skimmed dry milk-TBST solution were employed to probe their respective proteins. Incubation was performed at $4^{\circ} \mathrm{C}$ overnight. Membranes were washed with TBST (3x10 min washes) and incubated with HRP-conjugated secondary antibodies $(1: 1,000)$ of the appropriate species (mouse or rabbit) at room temperature for $2 \mathrm{~h}$. Following thorough washing of membranes, immunoreactive bands were visualized using the SuperSignal ${ }^{\circledR}$ West Pico Trial kit and detected with the ECL Gel Documentation and Analysis System (Bio-Rad, Hercules, CA, USA).

Statistical analysis. The data from all the experiments were expressed as the mean \pm standard deviation. Statistical analyses were performed with SPSS 13.0 software (SPSS Inc., Chicago, IL, USA). $\mathrm{P}<0.05$ was considered to indicate a statistically significant difference.

\section{Results}

Effects of EGCG on cell viability. To study the growth inhibitory effect of EGCG, HCCLM6 cells and HL-7702 liver cells were treated with 5-100 $\mu \mathrm{g} / \mathrm{ml}$ and 5-260 $\mu \mathrm{g} / \mathrm{ml}$ EGCG, respectively (Fig. 1). EGCG significantly inhibited the growth of HCCLM6 cells in a dose-dependent manner at concentrations between 10 and $100 \mu \mathrm{g} / \mathrm{ml}(\mathrm{P}<0.01$; Fig. 1A). The $\mathrm{IC}_{50}$ for HCCLM6 cells was $62 \mu \mathrm{g} / \mathrm{ml}$. By contrast, a much higher minimum dose of EGCG $(80 \mu \mathrm{g} / \mathrm{ml})$ was required to significantly inhibit the growth of HL-7702 liver cells $\left(\mathrm{P}<0.01\right.$; Fig. 1B), and the $\mathrm{IC}_{50}$ was $227 \mu \mathrm{g} / \mathrm{ml}$.

Cell death assessment. To assess the type of cell death induced by EGCG, the nuclei of EGCG-treated $(0,10$ or $30 \mu \mathrm{g} / \mathrm{ml})$ and untreated cells were stained with DAPI. The nuclei of 
A

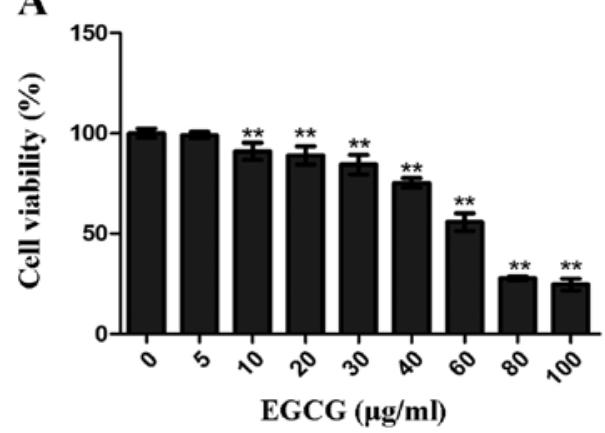

B

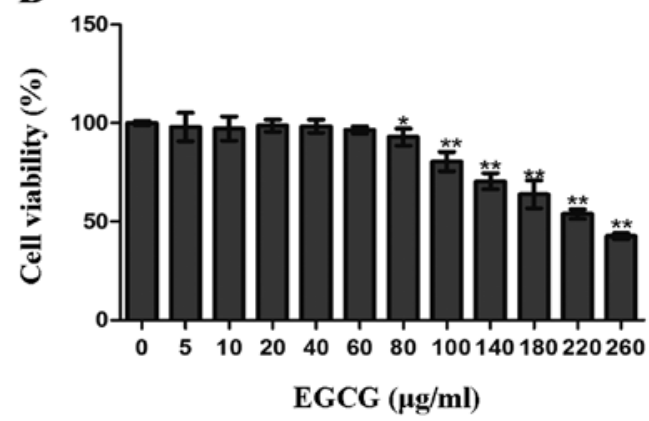

Figure 1. Growth inhibition of HCCLM6 and HL-7702 cells by epigallocatechin-3-gallate (EGCG). (A) HCCLM6 and (B) HL-7702 cells were grown in 96-well plates and treated with varying concentrations of EGCG for $24 \mathrm{~h}$. Growth inhibition was determined using the 3-(4,5-dimethylthiazol-2-yl)-2,5-diphenyltetrazolium bromide (MTT) assay. The data are expressed as the mean \pm standard deviation of five independent experiments $\left({ }^{*} \mathrm{P}<0.05\right.$ and ${ }^{* *} \mathrm{P}<0.01$ compared to the control).

a

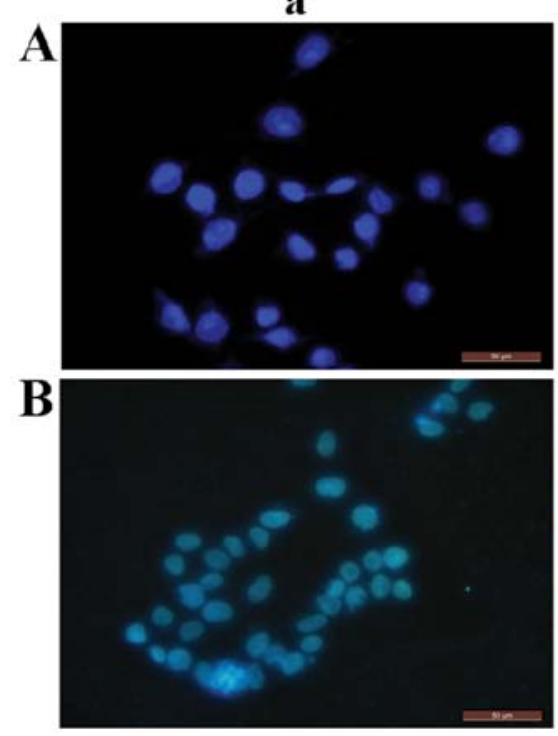

b
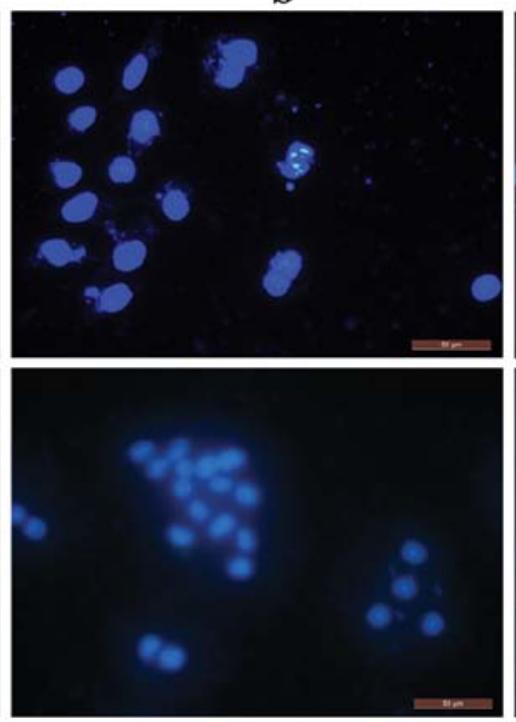

c
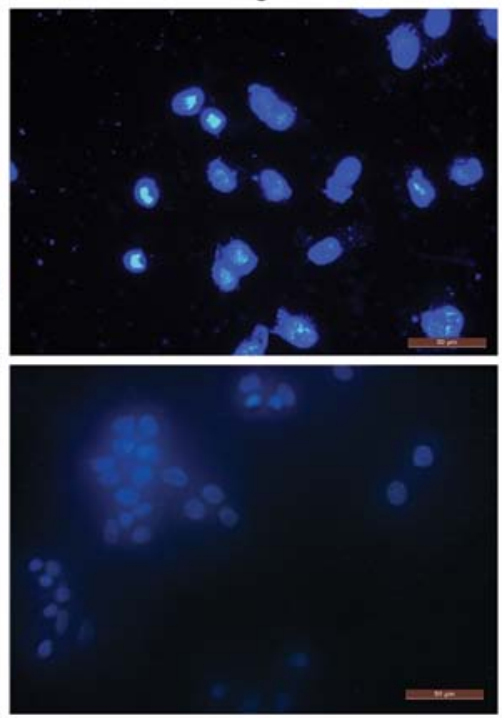

Figure 2. Epigallocatechin-3-gallate (EGCG) induces apoptotic-like cell death. (A) CCLM6 and (B) HL-7702 cells were treated with (a) 0 , (b) 10 or (c) $30 \mu$ g/ml EGCG for $24 \mathrm{~h}$ and examined for condensation and fragmentation of cellular nuclei with 4',6-diamidino-2-phenylindole (DAPI) staining. Scale bar, 50 $\mu \mathrm{m}$.

EGCG-treated non-viable HCCLM6 cells were predominantly condensed with nuclear morphological changes and DNA fragmentation (Fig. 2A-b and c) compared to untreated cells (Fig. 2A-a). This indicates that these cells underwent apoptotic-like cell death. Notably, HL-7702 cells that received a similar treatment were round in shape and had stable nucleus morphology with intact DNA integrity (Fig. 2B-a to c). This indicates that the HL-7702 cells did not undergo apoptotic-like cell death.

Effect of EGCG on cell apoptotic rate. To confirm the type of cell death induced by EGCG in HCCLM6 cells and to further evaluate the effects of EGCG on HL-7702 cells, a double-staining assay was conducted with Annexin V-FITC and PI. Annexin V-positive and PI-negative (Fig. 3, lower right quadrant) cell staining indicated early apoptosis. The cells that were strongly positive for Annexin V and PI (upper right quadrant) underwent late apoptosis/necrosis (23). EGCG treatment significantly increased the percentage of apoptotic HCCLM6 cells in a dose-dependent manner compared with untreated cells ( $\mathrm{P}<0.05$; Fig. 3A and B). HCCLM6 cells exposed to $10 \mu \mathrm{g} / \mathrm{ml}$ EGCG exhibited significant early apoptosis ( $\mathrm{P}<0.01$; Fig. $3 \mathrm{~B})$. Significant late apoptosis $(\mathrm{P}<0.05$; Fig. $3 \mathrm{~B})$ occurred only at $30 \mu \mathrm{g} / \mathrm{ml}$ EGCG. By contrast, neither 10 nor $30 \mu \mathrm{g} / \mathrm{ml} \mathrm{EGCG}$ caused significant early or late apoptosis in HL-7702 cells compared to untreated cells (Fig. 3C and D).

Effect of EGCG on the cell cycle. HCCLM6 cells treated with $30 \mu \mathrm{g} / \mathrm{ml}$ EGCG exhibited significant $\mathrm{G}_{0} / \mathrm{G}_{1}$ phase arrest compared to untreated cells (Fig. 4 and Table I). HL-7702 cells, however, did not exhibit phase arrest upon EGCG treatment (Fig. 4B and Table I). This indicates that EGCG is able to selectively induce cell cycle phase arrest in cancerous HCCLM6 cells but spares non-cancerous cells under similar treatment conditions.

Measurement of $\triangle \Psi_{m}$ in HCCLM6 and HL-7702 cells. MMP was measured using the mitochondria-specific lipophilic cationic fluorescent dye, JC-1. As a monomer, JC-1 is capable of selectively entering mitochondria. Under normal conditions, 
$\mathbf{A}$

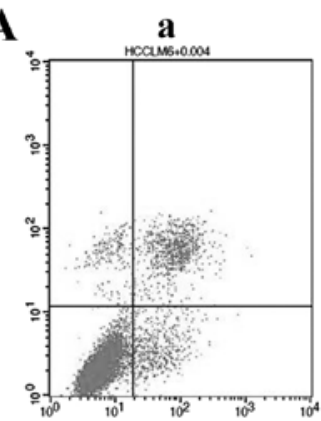

C

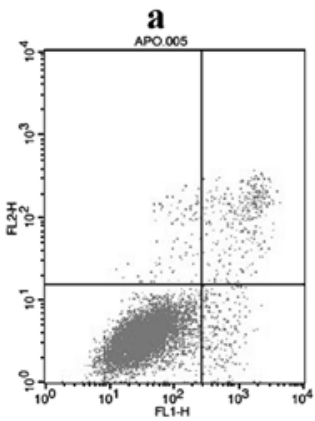

b

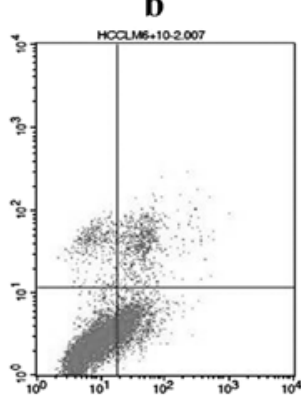

b

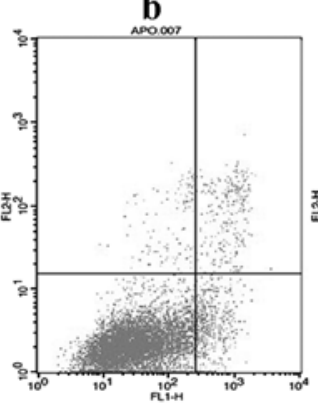

c

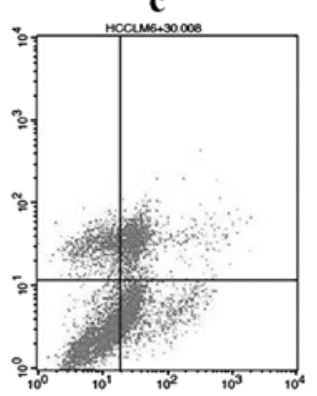

c

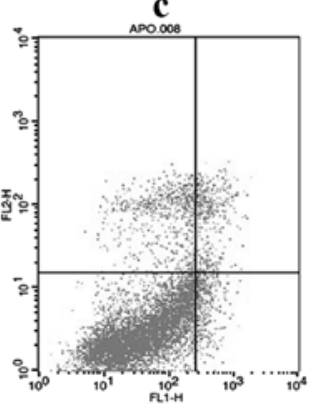

B

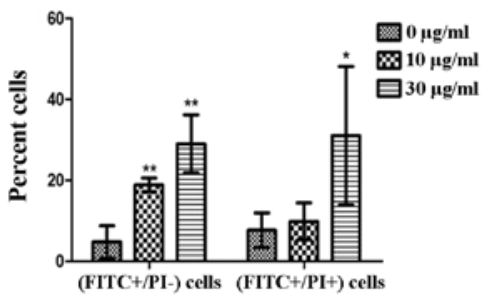

D

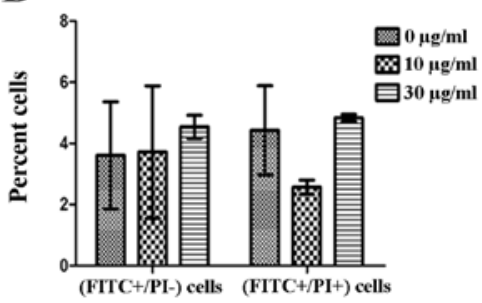

Figure 3. Flow cytometric quadrennial diagrams showing epigallocatechin-3-gallate (EGCG)-induced apoptotic rate and stage of (A) HCCLM6 and (C) HL-7702 cells. Cells were treated with (a) 0 , (b) 10 or (c) $30 \mu \mathrm{g} / \mathrm{ml}$ EGCG for $24 \mathrm{~h}$ and stained with Annexin V-fluorescein isothiocyanate (FITC) and propidium iodide (PI). The dot-plot results for three independent experiments are expressed as the percentage of early (first three bars) and late (last three bars) apoptotic (B) HCCLM6 and (D) HL-7702 cells.
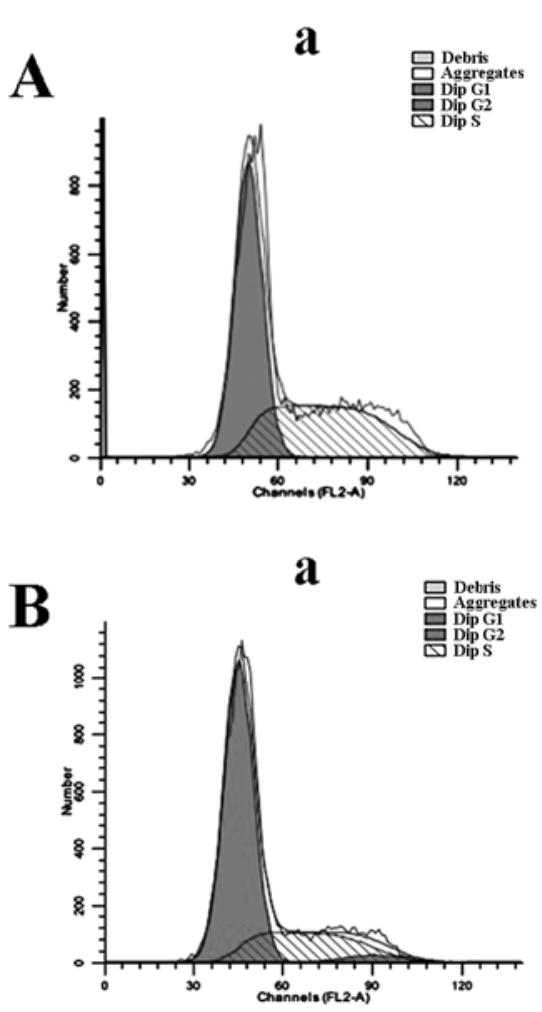

b

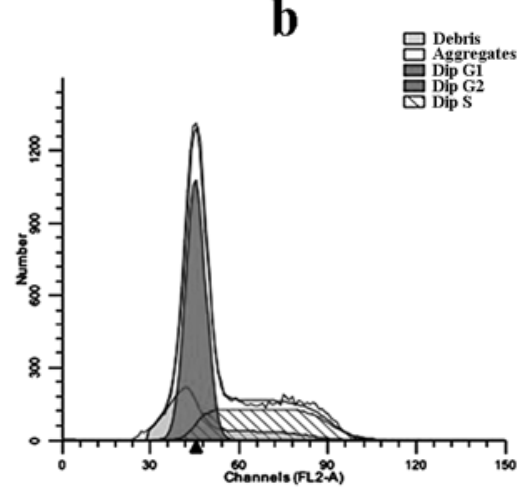

b

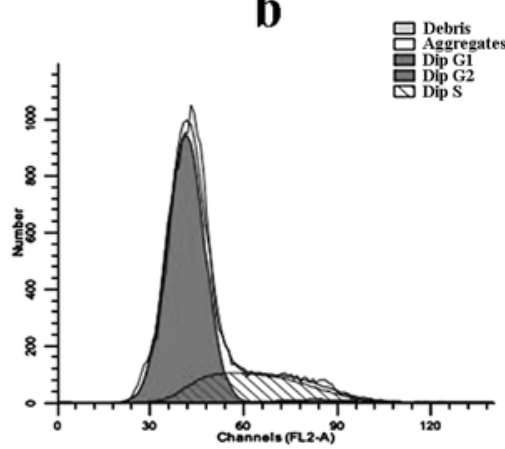

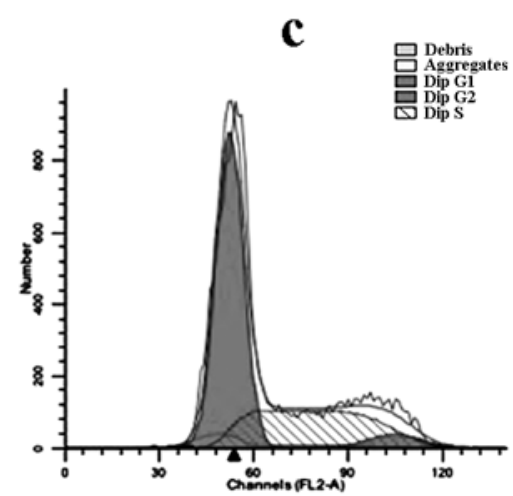

c

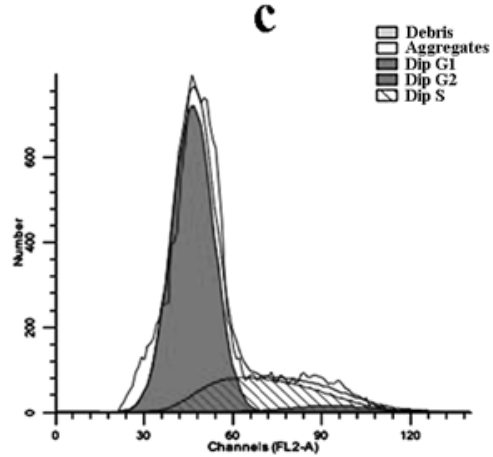

Figure 4. Flow cytometric analysis of the cell cycle by propidium iodide (PI) staining. (A) HCCLM6 and (B) HL-7702 cells were treated with (a) 0 , (b) 10 or (c) $30 \mu \mathrm{g} / \mathrm{ml}$ epigallocatechin-3-gallate (EGCG) for $24 \mathrm{~h}$ and stained with PI.

JC-1 aggregates within mitochondria and emits red fluorescence. However, when the MMP collapses during apoptosis, JC-1 emits green fluorescence. The dissipation of $\Delta \Psi \mathrm{m}$ was measured as an increase in green fluorescence.
Fig. 5A and C show the analysis of MMP in HCCLM6 and HL-7702 cells that were incubated with or without EGCG. Following 10 and $30 \mu \mathrm{g} / \mathrm{ml}$ EGCG treatment, HCCLM6 cells showed a significantly lower ratio of JC-1 aggregation in 
A

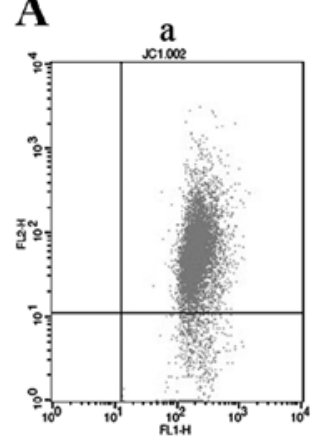

$\mathrm{C}$

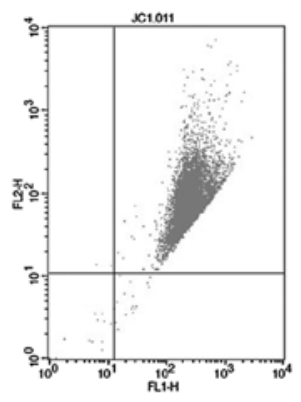

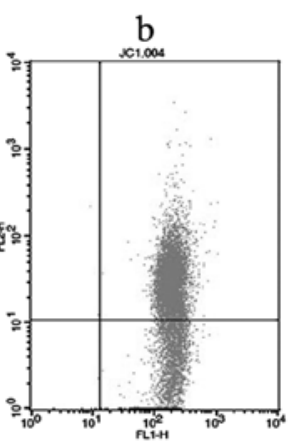
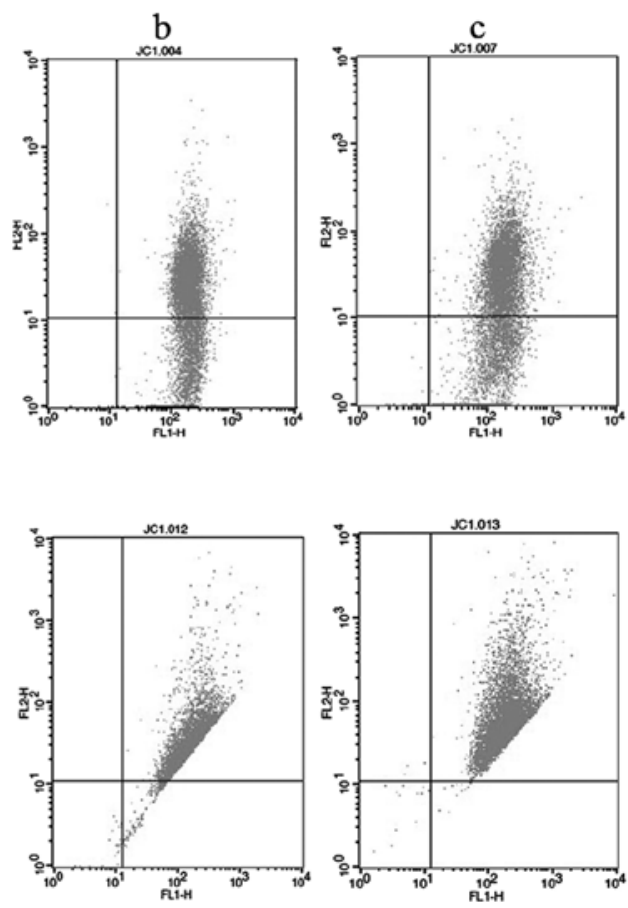

B
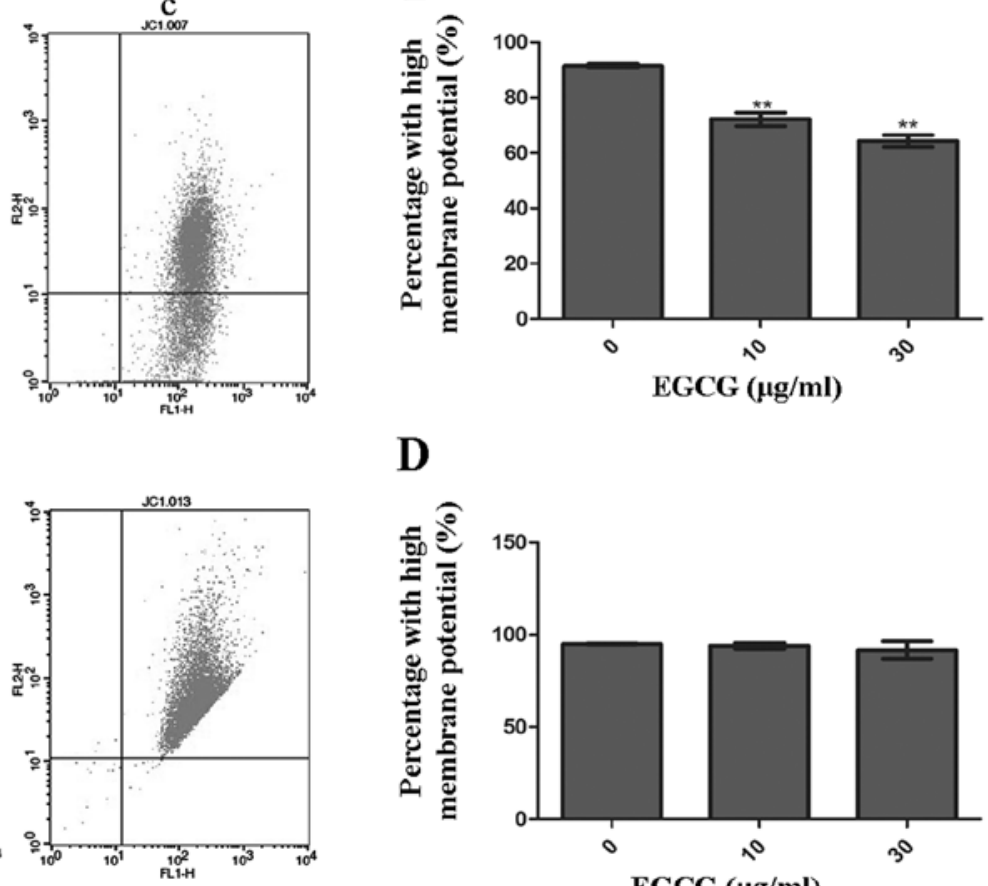

D

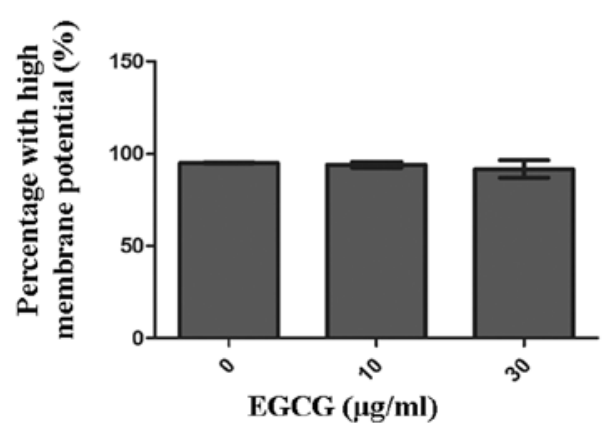

Figure 5. Flow cytometric analysis of mitochondrial membrane potential $(\Delta \Psi \mathrm{m})$ by JC-1 staining. (A) HCCLM6 and (C) HL-7702 cells were treated with (a) 0 , (b) 10 or (c) $30 \mu \mathrm{g} / \mathrm{ml}$ epigallocatechin-3-gallate (EGCG) for $24 \mathrm{~h}$ and stained with JC-1. The dot-plot results for three independent experiments are expressed as \% of (B) HCCLM6 and (D) HL-7702 cells with high $\Delta \Psi \mathrm{m}$.

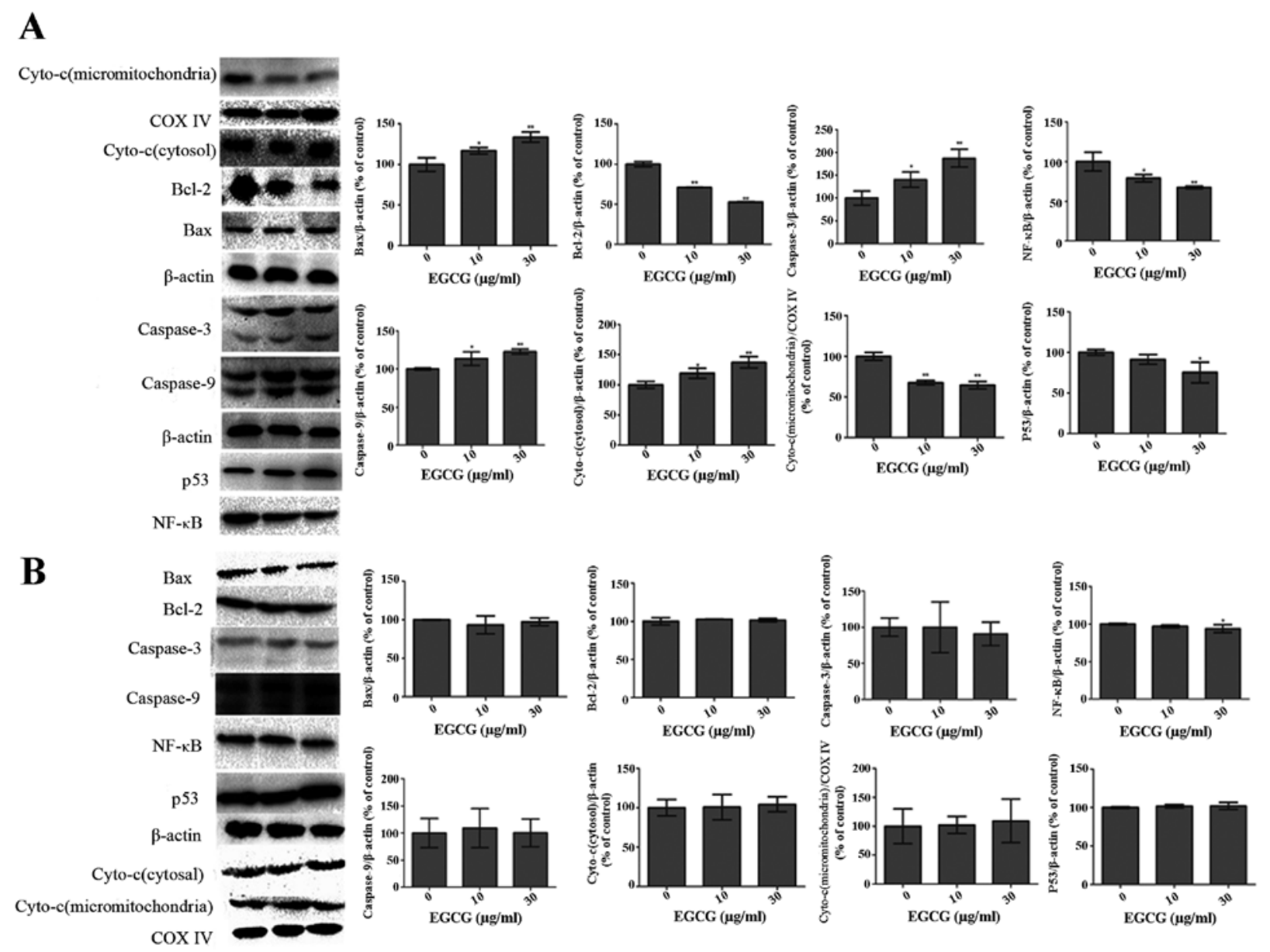

Figure 6. Western blot analysis of apoptosis-related proteins expressed by (A) HCCLM6 and (B) HL-7702 cells. The cells were treated with epigallocatechin-3-gal-

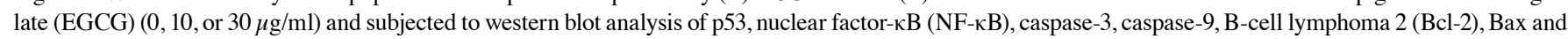
cytochrome $c$ expression. The data are expressed as the mean \pm standard deviation of three independent experiments ( $\mathrm{P}<0.05$ and ${ }^{* * *} \mathrm{P}<0.01$ compared to the control). 
Table I. Summary of the cell cycle phase distribution for epigallocatechin-3-gallate (EGCG)-treated and untreated HCCLM6 and HL-7702 cells.

\begin{tabular}{lccc}
\hline & \multicolumn{3}{c}{ Phase distribution } \\
\cline { 2 - 4 } \begin{tabular}{l} 
EGCG, \\
\cline { 2 - 4 }$/ \mathrm{ml}$
\end{tabular} & $\mathrm{G}_{0} / \mathrm{G}_{1}$ & $\mathrm{G}_{2} / \mathrm{M}$ & $\mathrm{S}$ \\
\hline HCCLM6 cells & & & \\
$\quad 0$ & $55.58 \pm 3.34$ & $0.0067 \pm 0.0058$ & $44.41 \pm 3.34$ \\
10 & $60.50 \pm 0.38$ & $1.66 \pm 1.22$ & $37.84 \pm 0.92$ \\
30 & $63.15 \pm 4.92^{\mathrm{a}}$ & $6.41 \pm 1.25^{\mathrm{b}}$ & $30.11 \pm 6.63^{\mathrm{b}}$ \\
HL-7702 cells & & & \\
0 & $73.20 \pm 2.58$ & $2.66 \pm 1.12$ & $24.15 \pm 1.46$ \\
10 & $72.90 \pm 3.81$ & $3.01 \pm 2.45$ & $23.13 \pm 0.00$ \\
30 & $73.80 \pm 0.71$ & $3.72 \pm 0.71$ & $21.47 \pm 1.41$ \\
\hline
\end{tabular}

${ }^{\mathrm{a}} \mathrm{P}<0.05$; ${ }^{\mathrm{b}} \mathrm{P}<0.01$, compared to the control. Data are expressed as the means \pm standard deviation of three independent experiments.

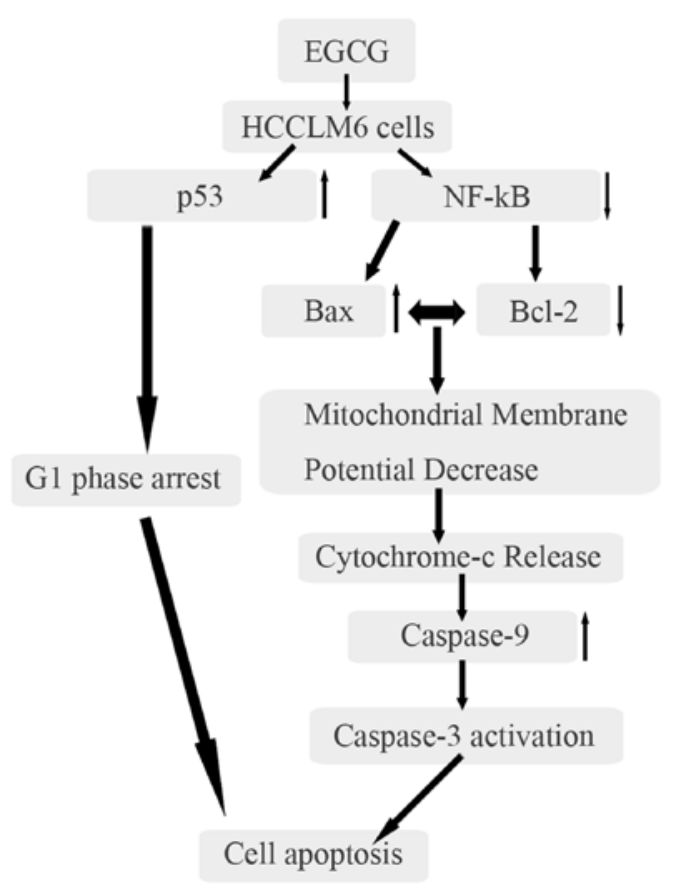

Figure 7. Proposed molecular mechanism of epigallocatechin-3-gallate (EGCG)-induced apoptosis of HCCLM6 cells.

mitochondria compared to untreated cells (Fig. 5B). However, there was no significant change in the $\Delta \Psi \mathrm{m}$ of HL-7702 cells, as indicated by the fairly constant JC-1 aggregation in the mitochondria of EGCG-treated and untreated cells (Fig. 5D).

Effect of EGCG on apoptotic proteins. Western blot analysis showed significantly lower expression of Bcl-2 and NF- $\kappa \mathrm{B}$ (Fig. 6A; P<0.01) in EGCG-treated HCCLM6 cells. Conversely, the expressions of Bax,p53, caspase-3 and caspase-9 were significantly increased $(\mathrm{P}<0.05)$ in a dose-dependent manner (Fig. 6A). EGCG treatment significantly reduced the expression of cytochrome $c$ in mitochondria but increased its expression in the cytosol of HCCLM6 cells (Fig. 6A). As shown in Fig. 6B, EGCG treatment did not significantly affect the expression of any of these proteins in HL-7702 cells, even at high EGCG concentrations.

\section{Discussion}

Apoptosis, a physiological death mechanism that preserves homeostasis, is the most common form of eukaryotic cell death (21). There are two major apoptotic pathways: The receptor-mediated (extrinsic) pathway and the mitochondrial-mediated (intrinsic) pathway (22). In the present study, the anticancer activity of EGCG was investigated. EGCG-induced cell death was observed to be apoptotic-like and characterized by cellular shrinkage, DNA fragmentation and the reduction of MMP (Figs. 1, 2 and 5). EGCG induced apoptosis of malignant HCCLM6 cells without inducing a similar effect on non-cancerous HL-7702 cells that received similar treatment (Figs. 3 and 4).

Apoptotic stimuli resulted in the loss of MMP and the release of cytochrome $c$ from the mitochondrial inner membrane space into the cytosol (23-26). The released cytochrome $c$, a potent caspase-activating protein, initiated the caspase-dependent apoptotic cascade. EGCG treatment caused a significant increase in the cytochrome $c$ levels in the cytosol and a concomitant reduction in the levels in the mitochondria of the HCCLM6 cells (Fig. 6A). The significantly increased expression of caspase-3 and -9 (Fig. 6) may be the direct result of the increased cytosolic cytochrome $c$ levels induced by EGCG in HCCLM6 cells but not in HL-7702 cells (Fig. 6A and B). Thus, apoptosis is increased in HCCLM6 cells.

Bax is present in its inactive form in the cytosol or loosely attached to intracellular membranes as a monomer. In apoptotic cells, activated Bax is translocated and integrated into mitochondrial membranes $(27,28)$. This event causes membrane permeabilization and release of cytochrome $c$ from the mitochondria. Cytochrome $c$ is subsequently complexed with apoptotic protease activating factor-1 and procaspase- 9 to form the apoptosome. Cytochrome $c$ recruits procaspase-3, which is cleaved and activated by caspase- 9 to induce apoptosis. The ratio of Bax/Bcl-2 is critical for cell survival such that an increase in Bax levels could shift the ratio in favor of apoptosis. EGCG induced an increase in Bax expression but a reduction in Bcl-2 (a major anti-apoptotic protein) expression in HCCLM6 cells. Thus, a higher Bax/Bcl-2 ratio favored the apoptosis of these cells compared to non-cancerous HL-7702 cells (Fig. 6A and B).

EGCG was found to effectively decrease NF- $\kappa \mathrm{B}$ translational activity in human HCCLM6 cells (Fig. 6A). The NF- $\kappa$ B protein stimulates cell survival and promotes cell proliferation, and increased $\mathrm{NF}-\kappa \mathrm{B}$ activity is associated with numerous cancers, including HCC. A previous study also indicates that $\mathrm{NF}-\kappa \mathrm{B}$ activates the expression of the anti-apoptotic protein Bcl-2 (29).

The increase in p53 expression in EGCG-treated HCCLM6 cells (Fig. 6A) was associated with increased cytosolic cytochrome $c$ and Bax expression. The p53 tumor suppressor gene is critically involved in cell cycle regulation, DNA repair and programmed cell death. This gene stimulates the release of 
cytochrome $c$ by transcriptionally increasing cytosolic Bax levels in certain human cell lines $(29,30)$. Ahmed et al (31) reported in 2000 that EGCG induces $\mathrm{G}_{0} / \mathrm{G}_{1}$ phase cell cycle arrest, which is an irreversible process that ultimately leads to apoptotic death of human carcinoma cells. Cell cycle perturbations are an important component of the cellular response to DNA damage $(32,33)$. In addition, p53 plays an important role in controlling the $\mathrm{G}_{1} / \mathrm{S}$ checkpoint. Some cells undergo cell cycle arrest in the $G_{1}$ phase in response to DNA damage (34). The present study results indicate that EGCG-induced $\mathrm{G}_{0} / \mathrm{G}_{1}$ cell cycle phase arrest of HCCLM6 cells occurs via increased expression of p53, which eventually results in apoptotic cell death.

The data indicated that EGCG treatment results in upregulation of Bax via p53 and downregulation of $\mathrm{Bcl}-2$ via $\mathrm{NF}-\kappa \mathrm{B}$. The overexpression of Bax and low expression of $\mathrm{Bcl}-2$ eventually led to mitochondrial membrane disintegration and the release of cytochrome $c$. During apoptosis, cytochrome $c$ release caused the activation of caspase- 9 through the formation of the multimeric apoptosome complex. Caspase- 9 activated caspase-3, which resulted in apoptosis (Fig. 7). Additionally, EGCG caused $G_{0} / G_{1}$ phase arrest of the HCCLM6 cell cycle via increased expression of p53.

In conclusion, EGCG affects HCCLM6 cells by inducing apoptosis, predominantly through the mitochondria-mediated apoptosis pathway. Although the concentrations of EGCG used in the present study are higher than those achievable by drinking tea or through EGCG oral administration $(35,36)$, higher plasma and/or organ-specific EGCG bioavailability is achievable through intravenous administration (37). The present study indicates that EGCG is an anticancer agent in the treatment of HCC. EGCG selectively induced apoptosis in cancerous cells with a minimal effect on non-cancerous cells. However, the present study only approximately assessed the role of mitochondrial dysfunction in EGCG-induced apoptosis. Therefore, further studies are required to investigate other pathways that may induce apoptosis in EGCG-treated cells, the effect of EGCG on diseased and healthy tissues in vivo and the relevant mechanisms for maintaining cell viability of non-tumor cells.

\section{References}

1. El-Serag HB and Mason AC: Rising incidence of hepatocellular carcinoma in the United States. N Engl J Med 340: 745-750, 1999.

2. Parkin DM, Bray F, Ferlay J and Pisani P: Estimating the world cancer burden: Globocan 2000. Int J Cancer 94: 153-156, 2001.

3. lkai I, Yamaoka Y, Yamamoto Y, Ozaki N, Sakai Y, Satoh S, Shinkura N and Yamamoto M: Surgical intervention for patients with stage IV-A hepatocellular carcinoma without lymph node metastasis: proposal as a standard therapy. Ann Surg 227: 433-439, 1998

4. Lee JS, Chu IS, Heo J, Calvisi DF, Sun Z, Roskams T, Durnez A, Demetris AJ and Thorgeirsson SS: Classification and prediction of survival in hepatocellular carcinoma by gene expression profiling. Hepatology 40: 667-676, 2004.

5. Song HY, Liu YK, Feng JT, Cui JF, Dai Z, Zhang LJ, Feng JX, Shen HL and Tang ZY: Proteomic analysis on metastasis-associated proteins of human hepatocellular carcinoma tissues. J Cancer Res Clin Oncol 132: 92-98, 2006.

6. Yang CS and Wang ZY: Tea and cancer. J Natl Cancer Inst 85: 1038-1049,1993.

7. Balentine DA, Wiseman SA and Bouwens LC: The chemistry of tea flavonoids. Crit Rev Food Sci Nutr 37: 693-704, 1997.

8. Mukhtar H and Ahmad N: Green tea in chemoprevention of cancer. Toxicol Sci 52 (Suppl 2): 111-117, 1999.
9. Singh BN, Shankar S and Srivastava RK: Green tea catechin, epigallocatechin-3-gallate (EGCG): mechanisms, perspectives and clinical applications. Biochem Pharmacol 82: 1807-1821, 2011

10. Thawonsuwan J, Kiron V, Satoh S, Panigrahi A and Verlhac V: Epigallocatechin-3-gallate (EGCG) affects the antioxidant and immune defense of the rainbow trout, Oncorhynchus mykiss. Fish Physiol Biochem 36: 687-697, 2010.

11. Mukhtar H and Ahmad N: Tea polyphenols: prevention of cancer and optimizing health. Am J Clin Nutr 71 (Suppl 6): 1698S-1702S, 2000

12. Thangapazham RL, Singh AK, Sharma A, Warren J, Gaddipati J and Maheshwari RK: Green tea polyphenols and its constituent epigallocatechin gallate inhibits proliferation of human breast cancer cells in vitro and in vivo. Cancer Lett 245: 232-241, 2007.

13. Stuart EC, Scandlyn MJ and Rosengren RJ: Role of epigallocatechin gallate (EGCG) in the treatment of breast and prostate cancer. Life Sci 79: 2329-2336, 2006.

14. Ahmad N, Feyes DK, Nieminen AL, Agarwal R and Mukhtar H: Green tea constituent epigallocatechin-3-gallate and induction of apoptosis and cell cycle arrest in human carcinoma cells. J Natl Cancer Inst 89: 1881-1886, 1997.

15. Masuda M, Suzui M and Weinstein IB: Effects of epigallocatechin-3-gallate on growth, epidermal growth factor receptor signaling pathways,gene expression, and chemosensitivity in human head and neck squamous cell carcinoma cell lines. Clin Cancer Res 7: 4220-4229, 2001.

16. Nihal M, Ahmad N, Mukhtar H and Wood GS: Anti-proliferative and proapoptotic effects of (-)-epigallocatechin-3-gallate on human melanoma: possible implications for the chemoprevention of melanoma. Int J Cancer 114: 513-521, 2005.

17. Gupta S, Hussain T and Mukhtar H: Molecular pathway for (-)-epigallocatechin-3-gallate-induced cell cycle arrest and apoptosis of human prostate carcinoma cells. Arch Biochem Biophys 410: 177-185, 2003.

18. Wei DZ, Yang JY, Liu JW and Tong WY: Inhibition of liver cancer cell proliferation and migration by a combination of (-)-epigallocatechin-3-gallate and ascorbic acid. J Chemother 15: 591-595, 2003.

19. Uesato S, Kitagawa Y, Kamishimoto M, Kumagai A, Hori H and Nagasawa H: Inhibition of green tea catechins against the growth of cancerous human colon and hepatic epithelial cells. Cancer Lett 170: 41-44, 2001

20. Nishikawa T, Nakajima T, Moriguchi M, Jo M, Sekoguchi S, Ishii M, et al: A green tea polyphenol, epigalocatechin-3-gallate, induces apoptosis of human hepatocellular carcinoma, possibly through inhibition of Bcl-2 family proteins. J Hepatol 44: 1074-1082, 2006

21. Wyllie AH, Kerr JF and Currie AR: Cell death: the significance of apoptosis. Int Rev Cytol 68: 251-306, 1980.

22. Soldatenkov VA and Smulson M: Poly (ADP-ribose) polymerase in DNA damage-response pathway: implications for radiation oncology. Int J Cancer 90: 59-67, 2000.

23. Wei MC, Zong WX, Cheng EH, Lindsten T, Panoutsakopoulou V, Ross AJ, et al: Proapoptotic BAX and BAK: a requisite gateway to mitochondrial dysfunction and death. Science 292: 727-730, 2001.

24. Green DR and Reed JC: Mitochondria and apoptosis. Science 281: 1309-1312, 1998

25. Marsden VS, O'Connor L, O'Reilly LA, Silke J, Metcalf D, Ekert PG, et al: Apoptosis initiated by Bcl-2-regulated caspase activation independently of the cytochrome $c /$ Apaf-1/caspase- 9 apoptosome. Nature 419: 634-637, 2002.

26. Tsujimoto Y: Cell death regulation by the Bcl-2 protein family in the mitochondria. J Cell Physiol 195: 158-167, 2003.

27. Kowaltowski AJ, Vercesi AE and Fiskum G: Bcl-2 prevents mitochondrial permeability transition and cytochrome $c$ release via maintenance of reduced pyridine nucleotides. Cell Death Differ 7: 903-910, 2000

28. Reed JC: Proapoptotic multidomain Bcl-2/Bax-family proteins: mechanisms, physiological roles, and therapeutic opportunities. Cell Death Differ 13: 1378-1386, 2006.

29. Schuler M, Bossy-Wetzel E, Goldstein JC, Fitzgerald P and Green DR: p53 induces apoptosis by caspase activation through mitochondrial cytochrome $c$ release. J Biol Chem 275: 7337-7342, 2000.

30. Miyashita T and Reed JC: Tumor suppressor p53 is a direct transcriptional activator of the human bax gene. Cell 80: 293-299, 1995. 
31. Ahmad N, Cheng P and Mukhtar H: Cell cycle dysregulation by green tea polyphenol epigallocatechin-3-gallate. Biochem Biophys Res Commun 275: 328-334, 2000.

32. Weinert TA and Hartwell LH: The RAD9 gene controls the cell cycle response to DNA damage in Saccharomyces cerevisiae. Science 241: 317-322, 1988.

33. Smerdon MJ, Kastan MB and Lieberman MW: Distribution of repair-incorporated nucleotides and nucleosome rearrangement in the chromatin of normal and xeroderma pigmentosum human fibroblasts. Biochemistry 18: 3732-3739, 1979.

34. Kastan MB, Canman CE and Christopher J: p53, cell cycle control and apoptosis: implications for cancer. Cancer Metastasis Rev 14: 3-15, 1995.
35. Chow HH, Cai Y, Hakim IA, Crowell JA, Shahi F, Brooks CA, Dorr RT, Hara Y and Alberts DS: Pharmacokinetics and safety of green tea polyphenols after multiple-dose administration of epigallocatechin gallate and polyphenon $\mathrm{E}$ in healthy individuals. Clin Cancer Res 9: 3312-3319, 2003.

36. Chow HH, Cai Y, Alberts DS, et al: Phase I pharmacokinetic study of tea polyphenols following single-dose administration of epigallocatechin gallate and polyphenon E. Cancer Epidemiol Biomarkers Prev 10: 53-58, 2001.

37. Li QS, Wang CY, Han GZ, Zou LL, Li L and Li N: Application of LC-MS/MS method in pharmacokinetic study of multi-components from tea polyphenols in rats. Chin J New Drugs 20: 817-823, 2011. 